\title{
Fragmentation Characteristics and Damage Capacity of Radial Layered PELE
}

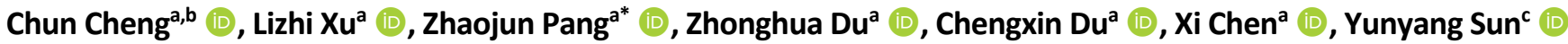 \\ aSchool of Mechanical Engineering, Nanjing University of Science and Technology, Nanjing 210094, China. Email: xiangchun893@163.com, \\ xulznjust@163.com, pangzj@njust.edu.cn, duzhonghua@aliyun.com, duchengxin4324@163.com, chenxi202@aliyun.com \\ bMOE Key Laboratory of Impact and Safety Engineering, Ningbo University, Ningbo 315211, China. Email: xiangchun893@163.com \\ cNanjing Research Institute of Inner Mongolia North Heavy Industry Group Co., Ltd, Nanjing 210094, China. Email: 1043581933@qq.com \\ *Corresponding author
}

https://doi.org/10.1590/1679-78256235

\begin{abstract}
PELE (the Penetrator with Enhanced Lateral Effect) produces a large number of fragments after penetrating metal target plate, which can damage the high-value targets behind the shield plate in a large area. However, when facing the multilayer spaced metal shield plates, it is difficult to penetrate them and damage the targets behind them due to the limited penetration ability of the fragments. Radial layered PELE was designed for damaging multi-layer spaced metal plates. The experiment and numerical simulation were carried out to study the deformation and fragmentation of the penetrator after penetrating 2A12 aluminum alloy or Q235 steel target plate at different velocities, as well as the damage to the witness plates after penetrating the main target plates. The results show that the fragmentation of PELE increases with the increase of impact velocity. At the same impact velocity and the same thickness of metal target plate, compared with penetrating the 2A12 aluminum alloy target plate, radial layered PELE is deformed and broken to a greater extent, resulting in heavier damage to the witness plates when penetrating the Q235 steel target plate. In the process of penetrating multi-layer metal target plates, the outer jacket of radial layered PELE is gradually broken to form a large number of flying fragments, but the inner jacket is difficult to deform and break, resulting in the strong penetration ability of the penetrator. Therefore, radial layered PELE has better penetration and damage capacity than non layered PELE.
\end{abstract}

\section{Keywords}

Radial layered PELE; Fragmentation; Damage capacity; Multi-layer spaced metal plates

\section{Graphical Abstract}

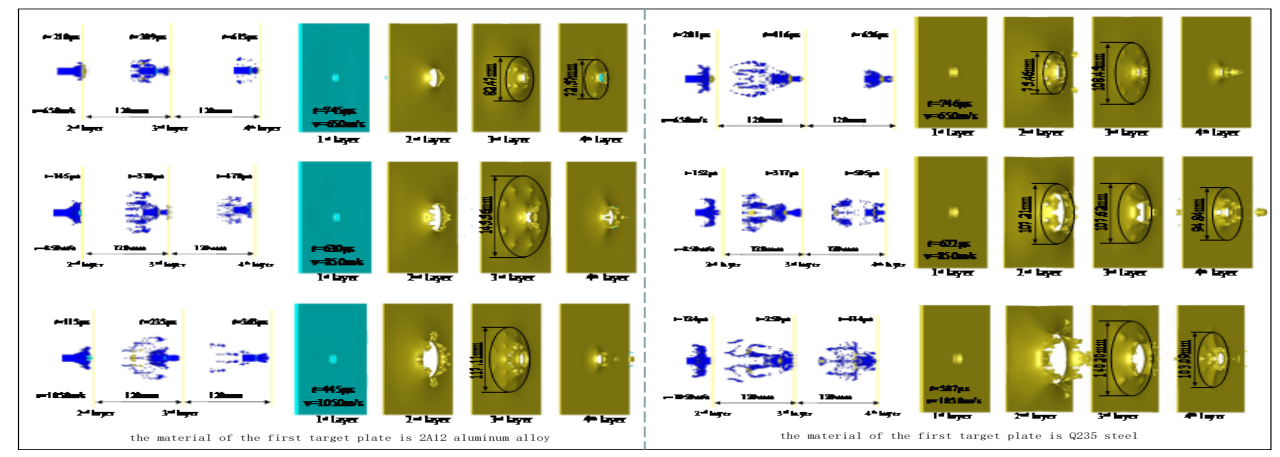

Received: April 01, 2020. In Revised Form: August 10, 2020. Accepted: September 01, 2020. Available online: September 21, 2020. https://doi.org/10.1590/1679-78256235

CC) Latin American Journal of Solids and Structures. ISSN 1679-7825. Copyright @ 9 2020. This is an Open Access article distributed under the terms of the Creative Commons Attribution License, which permits unrestricted use, distribution, and reproduction in any medium, provided the original work is properly cited. 


\section{INTRODUCTION}

PELE is composed of a high-density cylindrical jacket and a low-density filling. At the moment of impacting the metal target plate, the jacket is subjected to severe impact load. In the process of penetrating the target plate, the inner wall of the jacket is subjected to the radial force generated by the expansion of the filling and the outer wall of the jacket is subjected to the radial binding effect of the target plate. After penetrating the target plate, the radial binding effect of the target plate on the jacket disappears, and the jacket is broken and scattered under the radial force of the filling(Ding et al., 2018a).

Based on the theory of weak shock wave, the theory of impact pressure and duration of it on the filling is put forward (Paulus et al. 2006). It is believed that all the energy of jacket breaking comes from the pressure in the filling. On the basis of Paulus' research, the filling is an ideal elastic material assumed by Zhu, neglecting the energy consumption when the jacket deforms and breaks, combined with the Poisson effect of the filling, he thinks that the part of elastic energy caused by Poisson effect completely transforms to the radial flying kinetic energy of the fragments produced by the jacket breaking, and obtains the radial dispersion velocity formula of fragments(Zhu et al., 2009a). The research of Paulus and Zhu mainly focuses on the impact compression and expansion energy release of the filling, without considering the change of the jacket during the impact process. Based on plane wave theory and energy conservation, the maximum radial flying velocity of fragments produced by the jacket is considered to be the result of the common radial expansion of the jacket and filling under the impact of shock wave compression(Fan et al., 2017a, 2017b). In the calculation, the influence of the lateral expansion effect of the jacket and filling on the radial dispersion velocity of the fragments is considered simultaneously and the axial residual velocity and the radial velocity of the fragmentsare approximately calculated, as well as the minimum and maximum width of the fragments.

In the quantitative calculation of PELE penetrating the target plate, the pressure on the filling during impact is calculated based on the assumption of one-dimensional strain and the relationship of Rankine-Hugoniot. Then, the radial pressure between the filling and the jacket is calculated by using the generalized Hooke's law, the radial acceleration of the jacket is calculated, and the average mass of fragments is calculated by using the Mott ring fragmentation theory(Jimmy, 2015). Based on the kinetic energy principle and impulse theorem, a theoretical analysis model of the lateral velocity of the jacket is established by Du. The model comprehensively considered the influence of material characteristics of the jacket and the filling, the impact velocity, the length-diameter ratio, the inside-outside diameter ratio and the Poisson ratio on the lateral velocity of the jacket (Du et al., 2011).

Scholars have also studied the material selection of the jacket and the filling. Generally, the materials selected as the jacket are steel, tungsten alloy and ceramics(Fan et al., 2016, Yin et al., 2020, Ding et al., 2018b), and the materials selected as the filling are aluminum alloy, polyethylene, nylon and rubber(Zhu et al., 2007, Xu, et al., 2020). The research results show that the larger the jacket density is, the stronger the velocity storage capacity of PELE is; the larger the compression tensile strength ratio of jacket is, the larger the radial velocity of fragments is; the smaller the elastic modulus and the larger the Poisson ratio of the filling is, the smaller the radial velocity of fragments is. In addition, Zhu's research on the structure of the penetrator shows that for a specific material of the projectile and target plate, when the internal-external diameter ratio of the jacket is taken as $0.5-0.7$, and the length diameter ratio is taken as 3-5, PELE can not only easily penetrate the target plate, generate a large number of fragments with high radial velocity, which can effectively damaging the target in a large area (Zhu et al., 2009b).

PELE produces a lot of fragments after penetrating the metal target plate, which can damage the high-value target after the protective structure. However, in the face of multi-layer spaced metal plates, it is difficult to penetrate them and damage the target after the protective plates due to the limited penetration ability of the fragments. In this paper, based on a large number of previous studies, a PELE with radial layered structure is designed. In the process of passing through the multi-layer spaced metal plates, the outer jacket of the new structure PELE gradually breaks up to form a large number of flying fragments, but the inner jacket is relatively difficult to deform and break, so the penetrator maintains a strong penetration ability, result in that radial layered PELE has a better penetration and damage ability to the multi-layer spaced metal plates. In this paper, the experiment and numerical simulation were carried out to study the deformation and fragmentation of radial layered PELE perforating multi-layer spaced metal plates, and the influence of impact velocity and the material of the target plate on the fragmentation and the damage capacity of radial layered PELE to the multi-layer spaced metal plates.

\section{PELE EXPERIMENT}

The schematic diagram and pictures of radial layered PELE with tungsten alloy as jackets and nylon as fillings are shown in Figure 1 (a) and (b). The structural dimensions of non layered PELE and radial layered PELE used for experiment and numerical simulation in this paper are shown in Figure 1 (c) and (d). 
outer jacket inner jacket inner filling outer filling

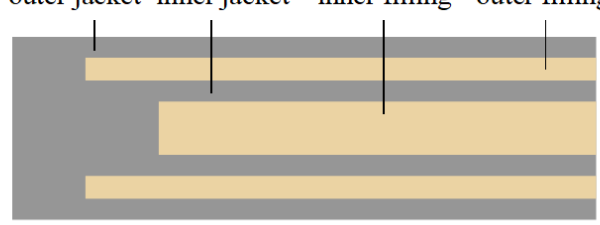

(a) Diagram of radial layered PELE

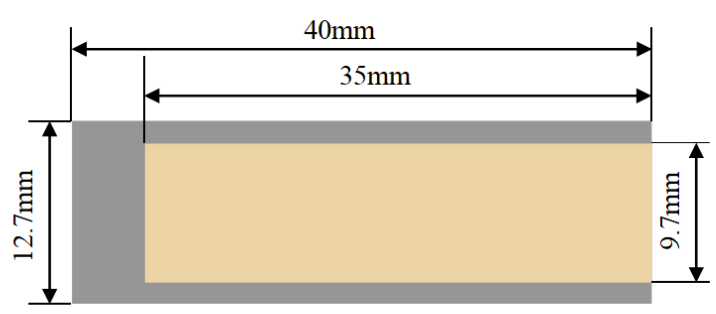

(c) Non layered PELE

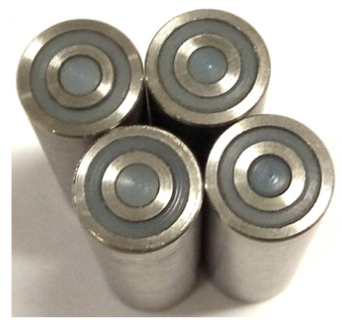

(b) Picture of radial layered PELE

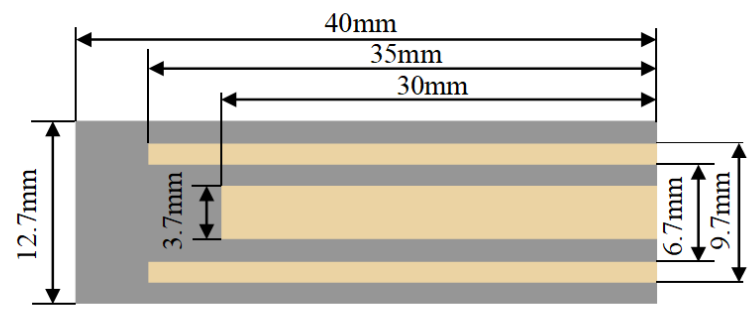

(d) Radial layered PELE

Figure 1 PELE used in the experiment and numerical simulation

In the experiment, the ballistic gun was used to launch the penetrator, and the velocity of the penetrator before hitting the target was measured by the on-off velocity meter. The diameter of the penetrator was $12.7 \mathrm{~mm}$ and the length was $40 \mathrm{~mm}$. In the first set of experiments, the main target plate was $2 \mathrm{~A} 12$ aluminum alloy plate with the size of $400 \times 400 \times 5 \mathrm{~mm}$, the witness plates were Q235 steel plates with the size of $400 \times 400 \times 2 \mathrm{~mm}$, and the distance between the target plates was $150 \mathrm{~mm}$. In the second set of experiments, the main target plate was Q235 steel plate with the size of $400 \times 400 \times 5 \mathrm{~mm}$, the witness plates were Q235 steel plates with the size of $400 \times 400 \times 2 \mathrm{~mm}$, and the distance between the target plates was $150 \mathrm{~mm}$. The experimental set-up is shown in Figure 2.

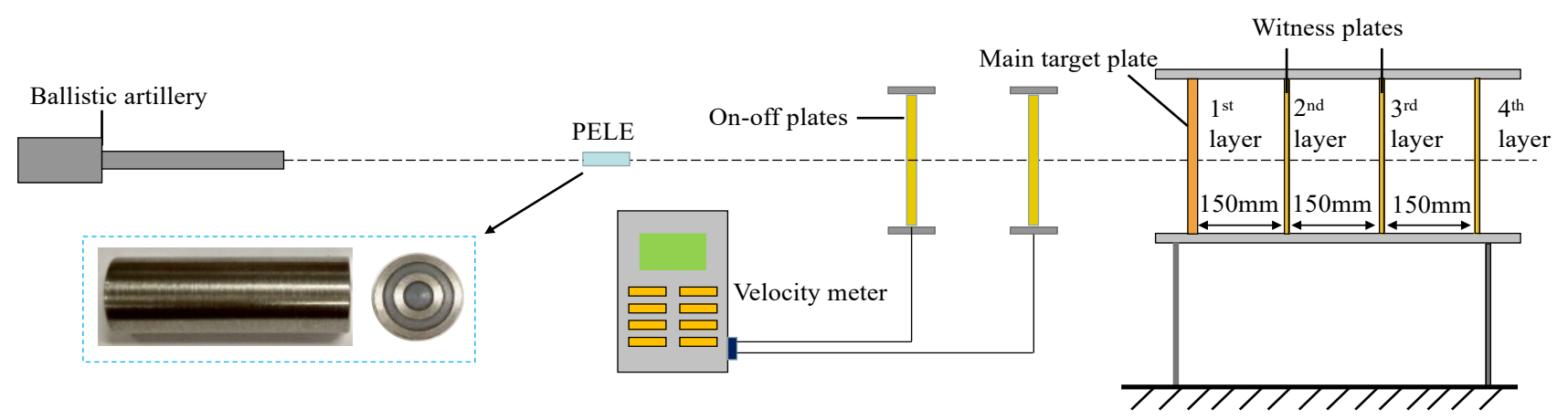

Figure 2 Experimental set-up

When the main target plate is $2 \mathrm{~A} 12$ aluminum alloy plate and the impact velocity is $653.3 \mathrm{~m} / \mathrm{s}$, the damage of the witness plates is shown in Figure 3(a). An elliptical perforation is formed on the second target plate, with the size of about $33 \mathrm{~mm} \times 50 \mathrm{~mm}$. On the third target plate, there is a approximately rectangular hole and a small number of impact craters, which indicates that the attitude of the penetrator has changed greatly after penetrating the second target plate, that means the penetrator impacts the thired target plate obliquely. From the perforation profile, it can be seen that the overall deformation of the penetrator is relatively large. Although the bottom of the penetrator is basically not deformed, the middle part of the penetrator bulges and there is small deformation at the head. This indicates that after penetrating the first target plate, the head of the outer jacket is broken. The fragments work together with the residual penetrator forming a large perforation on the second target plate. The results of experiments are the same as those of numerical simulation, they all shown that after penetrating the first target plate, the head of outer jacket head is broken, but the deformation and breaking degree of other parts of the penetrator are small. When the main target plate is Q235 steel plate and the impact velocity is $657.2 \mathrm{~m} / \mathrm{s}$, the damage of the witness plates is shown in Figure $3(\mathrm{~b})$. In the center of the second target plate, a diamond shaped perforation with a side length of about $38 \mathrm{~mm}$ is formed, and the contour of the 
perforation is uneven. There are three pieces of perforation and four pits left by fragments around the perforation, which indicates that the penetrator has been broken to a large extent. The central perforation of the third target plate is relatively large, and the perforation is approximately circular, with a diameter of about $45 \mathrm{~mm}$. The flanging of perforation on the back of target plate is uneven and there are some perforations and dents left by fragments around the uneven perforation.

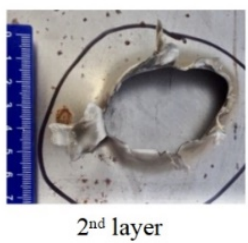

(a) 2 A12 aluminum alloy with $v=653.3 \mathrm{~m} / \mathrm{s}$

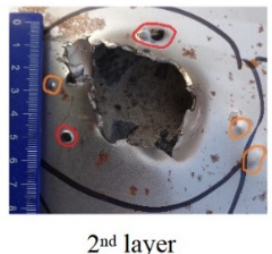

(b) Q235 steel with v=657.2 m/s

Figure 3 Damage pattern of the two witness plates at different impact velocities.

The experimental results show that radial layered PELE is deformed and broken after penetrating the 2A12 aluminum alloy target plate with the thickness of $5 \mathrm{~mm}$ or the Q235 steel target plate with the same thickness. However, when the target plate is Q235 steel plate, the deformation and fragmentation degree of the penetrator is greater than that of 2A12 aluminum alloy plate. It also can be seen that radial layered PELE has a good damage effect on each witness plate.

\section{THEORETICAL ANALYSIS}

The difference between radial layered PELE and the ordinary non layered PELE of the same caliber is that a layer of shell which is coaxial with the penetration outer shell is added to the space position of the filling, and the filling is divided into two parts: cylindrical shell and cylinder. The outermost shell of the penetrator is labeled as the outer jacket, and the inner metal shell is the inner jacket. The cylindrical shell and the cylinder fillings are labeled as the outer and inner filling respectively. Compared with ordinary non layered PELE of the same caliber, due to the appearance of the inner jacket, the overall volume of the filling decreases, the overall density of the penetrator increases, and the overall penetration ability of the penetrator increases. Using the shock wave parameters simply calculated by Rankine-Hugoniot conservation equation(Meyer, et al., 1981), it can be seen that the pressure in the penetrator when it impacts the target plate is

$$
P_{1}=\rho_{01} C_{1}\left(v-U_{P 2}\right)+\rho_{02} S_{1}\left(v-U_{P 2}\right)^{2}
$$

Where $\rho_{01}$ and $\rho_{02}$ are the densities of the penetrator and the target pate respectively; $v$ is the impact velocity; $C_{1}$ is the velocity of sound in the projectile when the pressure is zero; $S_{1}$ is the parameter in the equation of state of the penetrator material; $U_{P 2}$ is the particle velocity behind the wave front in the target plate.

From the pressure formula, it can be seen that the pressure in the penetrator is positively related to the density of the penetrator and the target plate, the impact velocity of the penetrator on the target plate, and the velocity of sound in the material of the penetrator. It can be inferred that if the PELE is assumed to be a homogeneous penetrator, the density, elastic modulus and sound velocity of radial layered PELE with a larger proportion of tungsten alloy are higher than those of non layered PELE. At the same impact velocity, when impacting the same metal target plate, the overall pressure on radial layered PELE is greater than that on non layered PELE, and the corresponding pressure on the target plate is also greater, which results in the accelerated destruction speed of the target plate, the reduced penetration time of the penetrator through the target plate, and the reduced pressure duration of the target plate on the filling. In addition, due to the decrease of volume, cross-sectional area, pressure and pressure duration, the volume expansion of PELE filling will be reduced. Therefore, compared with non layered PELE, radial layered PELE has a stronger penetration capability, while non layered PELE is more likely to break up and generate lateral flying fragments. However, when the target resistance is large enough and the pressure action time is long enough (that is, when the impact velocity and target thickness reach or exceed a certain range), radial layered PELE will also break up and generate fragments. Moreover the outer jacket is more easily broken than the inner jacket. 


\section{NUNERICAL SIMULATION}

If a reasonable constitutive and damage model is selected, the numerical simulation can accurately express the deformation and failure process of materials under extreme loads(Liu et al., 2019, 2020). Therefore, the numerical simulation was used to study the deformation and fragmentation of radial layered PELE perforating multi-layer spaced metal plates and influence of the impact velocity and the material of the target plate on the fragmentation and damage capacity of radial layered PELE to the multi-layer spaced metal plates.

\subsection{Numerical model}

AUTODYN code was used in numerical simulation. The penetrator was discretized by Smooth particle hydrodynamics (SPH) particles, and the target mesh was hexahedral Lagrangian mesh. The SPH method is a mesh-less numerical method based on Lagrange method, which has great attraction in simulating the dynamic response of material such as fracture and fragmentation(Moxnes et al., 2015), so the SPH method was used to simulate the fragmentation process of the jacket. In numerical simulation, it is very important to capture the plastic growth of materials under extreme loads(Liu et al., 2018). The Johnson-Cook strength model(Rohr et al., 2008) was used to describe the deformation and failure behavior of tungsten alloy jacket in the process of PELE penetrating target plate. Based on the brittle fracture behavior of tungsten alloy, especially high density tungsten alloy under dynamic loading, the tensile principal stress failure criterion describing the failure of brittle materials was added to the Johnson-Cook strength model in the fracture simulation of PELE jacket. Stochastic failure model based on Mott's theory(Mott, 1947) was introduced to the failure criterion of tensile principal stress in numerical simulation. The experimental results show that the numerical model can effectively simulate the fragmentation of PELE(Cheng et al., 2019). In order to study the influence of impact velocity and target material on radial layered PELE, 2A12 aluminum alloy and Q235 steel were selected as the main target materials. The thickness of the main target was $5 \mathrm{~mm}$, and the impact velocities were $450 \mathrm{~m} / \mathrm{s}, 650 \mathrm{~m} / \mathrm{s}, 850 \mathrm{~m} / \mathrm{s}$ and $1050 \mathrm{~m} / \mathrm{s}$, respectively. The witness target plate was made of three layers of Q235 steel plate with the thickness of $2 \mathrm{~mm}$, and the spacing between them was $120 \mathrm{~mm}$. The diameter of the penetrator was $12.7 \mathrm{~mm}$ and the length was $40 \mathrm{~mm}$. The non layered PELE with the same overall dimension was selected as the comparative analysis object as shown in Figure 1 (c). The numerical simulation model is shown in Figure 4. The main material properties of tungsten alloy, Q235 steel and $2 \mathrm{~A} 12$ aluminum alloy are shown in Table 1(Cheng et al., 2020, Zhang et al., 2013).

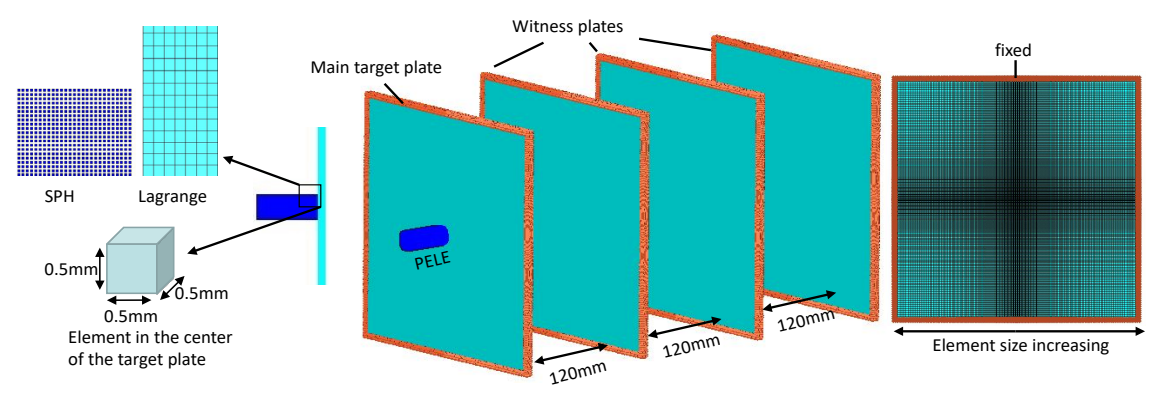

Figure 4 Numerical simulation model

Table 1 The main material properties of tungsten alloy, 2A12 aluminum alloy andQ235 steel

\begin{tabular}{cccc}
\hline & tungsten alloy & 2A 12 aluminum alloy & Q235 \\
\hline Density g/cm & 17.6 & 2.77 & 7.83 \\
Poisson's ratio & 0.3 & 0.33 & 0.33 \\
Modulus of elasticity/GPa & 360 & 71.7 & 210 \\
Static yield stress/MPa & 680 & 497 & 294 \\
Hardening constant/MPa & 177 & 310 & 230 \\
Thermal softening coefficient & 1 & 1.426 & 0.757 \\
Hardening exponent & 0.12 & 0.185 & 0.36 \\
Melting temperature/K & 1723 & 863 & 1795 \\
Specific heat capacity/J(kgK) & 134 & 921 & 469 \\
\hline
\end{tabular}




\subsection{Numerical results and analysis}

\subsubsection{Deformation and fragmentation of penetrator after perforating main target plate}

When the main target plate is 2A12 aluminum alloy plate with the thickness of $5 \mathrm{~mm}$, the deformation and fragmentation of the penetrator penetrating the target plate are shown in Figure 5. For non layered PELE, with the increase of impact velocity, the larger the deformation of the penetrator after penetrating the target plate, which shows that the length of the deformed part of the jacket increases, and the diameter of the jacket at the head of the penetrator increases. When the impact velocity is $450 \mathrm{~m} / \mathrm{s}$, the overall deformation of the penetrator is not large after non layered PELE and radial layered PELE penetrated the main target plate, only a small amount of deformation occurs at the head of the penetrator. For non layered PELE, the diameter of the jacket at the head of the penetrator increases due to the expansion of the filling, and the plug formed by the target plate is a circular platform shape. However, the diameter of the head of radial layered PELE decreases, which is due to the fact that the squeezing pressure of the target plate on the penetrator is greater than the radial force on the jacket caused by the expansion of the filling. In addition, the shape of the plug is approximately cylindrical, and there is a bulge on the back of the plug. When the impact velocity is $650 \mathrm{~m} / \mathrm{s}$, after penetrating the target plate, the deformation length of the outer jacket of radial layered PELE is longer than that of non layered PELE, while when the impact velocity is $850 \mathrm{~m} / \mathrm{s}$ and $1050 \mathrm{~m} / \mathrm{s}$, after penetrating the target plate, the deformation length of the outer jacket of radial layered PELE is smaller than that of non layered PELE, but the diameter of the penetrator head is basically the same. The plugs formed by non layered PELE penetrating $2 \mathrm{~A} 12$ aluminum alloy target plate are all in the shape of a circular platform, while the plugs formed by radial layered PELE penetrating $2 A 12$ aluminum alloy target plate are approximately cylindrical at a low speed $(450 \mathrm{~m} / \mathrm{s})$, irregular at a high speed $(650 \mathrm{~m} / \mathrm{s}$, $850 \mathrm{~m} / \mathrm{s}$ ), and composed of two parts, i.e. an approximate ring and an approximate cylinder at an impact velocity of $1050 \mathrm{~m} / \mathrm{s}$. With the increase of impact velocity, the deformation length and head diameter of the outer jacket after radial layered PELE penetrating the target plate increase, but when the velocity is less than $1050 \mathrm{~m} / \mathrm{s}$, the deformation of the inner jacket is not large, and when the impact velocity is $1050 \mathrm{~m} / \mathrm{s}$, the inner jacket appears obvious deformation.

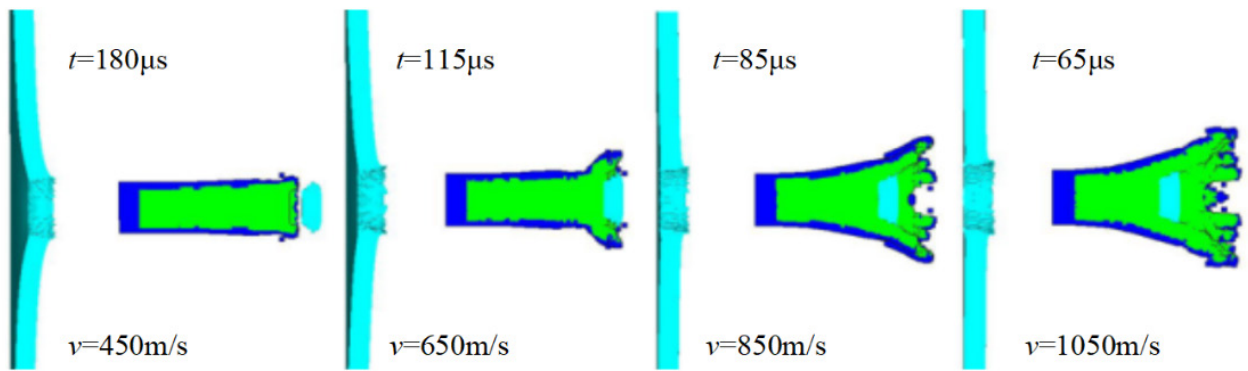

(a) Non layered PELE
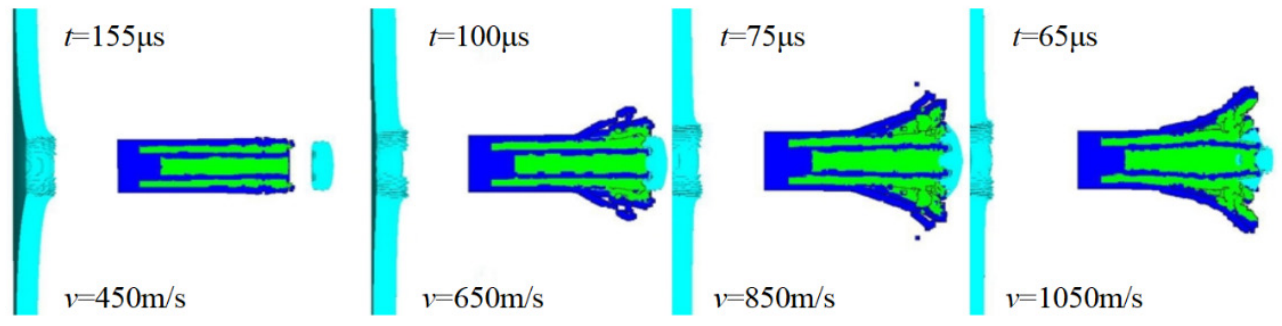

(b) Radial layered PELE

Figure 5 Deformation and fragmentation of penetrator after penetrating $2 \mathrm{~A} 12$ aluminum alloy main target plate with the thickness of $5 \mathrm{~mm}$

When the main target plate is Q235 steel with the thickness of $5 \mathrm{~mm}$, the deformation and fragmentation of the penetrator penetrating the target plate are shown in Figure 6. With the increase of impact velocity, the deformation and fracture degree of non layered PELE and radial layered PELE increase. The plug formed by non layered PELE punching target plate is also a circular platform shape. Under the same impact velocity, after penetrating the target plate, the deformation and fracture degree of the jacket of non layered PELE is greater than that of the outer jacket of radial layered PELE. When the impact velocity is $450 \mathrm{~m} / \mathrm{s}$, the failure of the head of non layered PELE jacket is obvious compression shear failure, and the failure after the head is mainly the tensile fracture caused by the expansion of the filling. Compression shear failure also occurs at the head of the outer jacket of the radially layered PELE, and compression 
expansion occurs at the outer filling. When the impact velocity is $450 \mathrm{~m} / \mathrm{s}$ and $650 \mathrm{~m} / \mathrm{s}$, the plug formed by radial layered PELE punching target plate is irregular. the plug is not completely squeezed into the inner filling, so the deformation of the inner filling and the inner jacket is small; when the impact velocity is $850 \mathrm{~m} / \mathrm{s}$ and $1050 \mathrm{~m} / \mathrm{s}$, the plug is composed of two parts, i.e. the approximate ring and the approximate cone. The inner filling is obviously compressed and expanded, so the inner jacket is also deformed to a large extent.

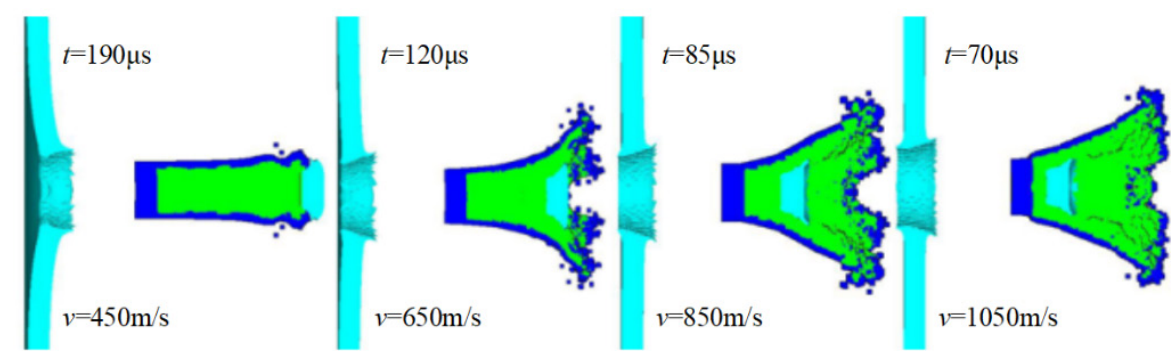

(a) Non layered PELE

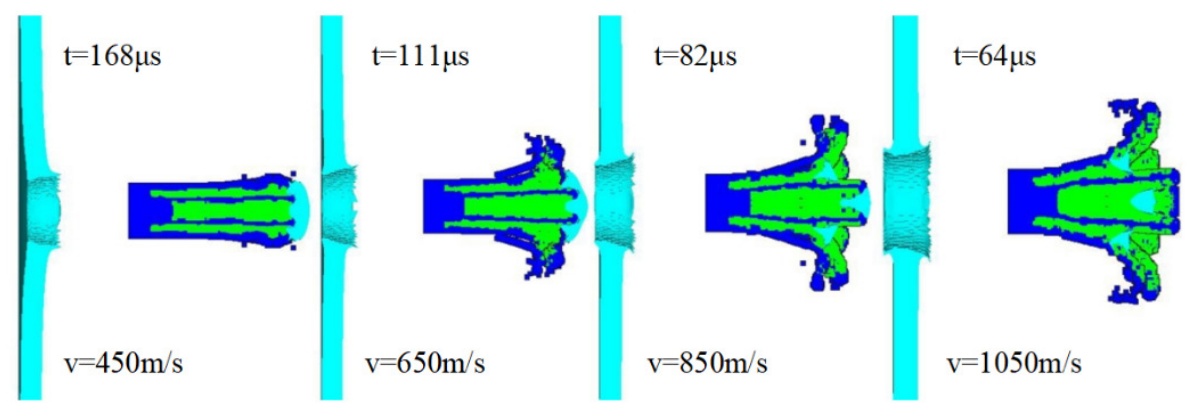

(b) Radial layered PELE

Figure 6 Deformation and fragmentation of penetrator after penetrating Q235 steel main target plate with the thickness of $5 \mathrm{~mm}$

The following conclusions can be drawn from the above analysis, when the impact velocity is the same, the material and thickness of the target plate are the same, the deformation and fragmentation degree of radial layered PELE after penetrating the target plate is less than that of non layered PELE. When radial layered PELE penetrates the target plate with the same thickness at the same velocity, the deformation and fragmentation degree of the penetrator after penetrating the Q235 steel plate is greater than that of the 2A12 aluminum alloy target plate. With the increase of impact velocity, the deformation and fragmentation of radial layered PELE after penetrating the target plate increase, and the diameter of fragments dispersion also increases.

\subsubsection{Damage capacity of radial layered PELE}

When the impact velocity is low, the deformation of PELE after penetrating the main target is not large. The impact effect of the penetrator on the multi-layer spaced witness metal plates can be approximately regarded as the shear plug failure of the thin plate subjected to flat head projectile. The penetrator is basically cylindrical, and the kinetic energy consumed by the target plate is transformed into the plastic deformation energy and shear failure energy, and the failure form of the target plate is plastic large deformation and perforation. When the impact velocity is large, the penetrator is seriously broken, and the damage of the penetrator to the multi-layer spaced witness metal plates can be regarded as the cooperative damage of multiple fragments to the thin plate. The damage form of the thin plate is not only the plastic deformation and perforation, but also the small perforation or impact crater formed by a large number of fragments. In this paper, the damage degree of target plate and the damage capacity of the penetrator are evaluated by using perforation diameter, small perforation or impact crater dispersion diameter, maximum plastic deformation diameter and plastic uplift height. In the following analysis, the main target plate is marked as the first target plate, and the witness plates were labeled as the second, third and fourth target plates.

Figure 7 and Figure 8 show the fragmentation and damage to the witness plates of non layered PELE and radial layered PELE after penetrating the main target plate of 2A12 aluminum alloy with the thickness of $5 \mathrm{~mm}$ at different velocities. It can be seen from Figure 7 that when the impact velocity is $450 \mathrm{~m} / \mathrm{s}$, the plug formed after non layered PELE penetrates the first target plate does not squeeze into the filling, and the deformation of the penetrator is small. The damage of the penetrator to the second target plate is mainly plugging failure. The 
perforation with a diameter of about $20.62 \mathrm{~mm}$ is formed on the target plate, and the large plastic deformation occurs around the perforation, the uplift height and the diameter of the plastic deformation area are about $15.67 \mathrm{~mm}$ and $173.60 \mathrm{~mm}$ respectively. After penetrating the second target plate, the jacket of the penetrator gradually breaks. In addition to the perforation (about $27.63 \mathrm{~mm}$ in diameter) and plastic deformation ( $21.44 \mathrm{~mm}$ in height and $180.61 \mathrm{~mm}$ in diameter) formed by the punching of the penetrator, there are also impact craters and plastic deformation formed by the impact of the fragments produced by the penetrator on the target plate. The distribution diameter of the impact craters is about $65.98 \mathrm{~mm}$. After the penetrator penetrates the third target plate, the jacket of the penetrator continues to break, but the cylinder part of the jacket is not completely broken. The penetrator forms a perforation with a diameter of about $20.62 \mathrm{~mm}$ on the fourth target plate and impact craters with a scattered diameter of about $59.79 \mathrm{~mm}$. The diameter and uplift height of plastic deformation area on the fourth target plate are about $120.41 \mathrm{~mm}$ and $18.14 \mathrm{~mm}$ respectively.

When the impact velocity is $650 \mathrm{~m} / \mathrm{s}$, non layered PELE starts to break after penetrating the first target plate. Before hitting the fourth target plate, the jacket of the penetrator has been completely broken. However, the radial dispersion velocity of the fragments produced by the breaking of the penetrator is small, and the distribution of the fragments is relatively concentrated. The damage of the penetrator to the target plate is mainly the perforation and the plastic deformation around the perforation. Holes with diameters of $36.70 \mathrm{~mm}$, $55.26 \mathrm{~mm}$ and $26.29 \mathrm{~mm}$ are formed on the second, third and fourth target plates, respectively, and there are obvious tear marks on the perforation edge of the third target plate.

When the impact velocity is $850 \mathrm{~m} / \mathrm{s}$, non layered PELE starts to break after penetrating the first target plate. Before hitting the third target plate, the jacket of the penetrator has been completely broken, and the scattered area of fragments is relative large. The penetrator formed a large tear hole on the second target plate with a diameter of $69.28 \mathrm{~mm}$. A large number of fragments generated by the fragmentation of the penetrator form a large number of impact craters and large plastic deformation on the third target plate. The diameter of the crater distribution is about $146.39 \mathrm{~mm}$, and the center dense fragments form a hole with a diameter of about $50.72 \mathrm{~mm}$ on the third target plate. The impact craters with large scattering area is also formed on the fourth target plate by the penetrator, but he number of craters is less than the number of craters on the third target plate, and the plastic deformation and perforation diameter (about $21.44 \mathrm{~mm}$ ) are also less than those on the third target plate. When the impact velocity is $1050 \mathrm{~m} / \mathrm{s}$, the fragmentation of the penetrator and the damage to the target plate are similar to those at the impact velocity of $850 \mathrm{~m} / \mathrm{s}$. The difference is that after penetrating the first target plate, the fragmentation degree of the penetrator is greater, which means that the number of fragments produced by the fragmentation of the penetrator is more, and the average mass of fragments is smaller. Specifically, the perforation diameter of on the second target plate is larger (about $75.05 \mathrm{~mm}$ ), and a large area of impact craters is formed on the third target plate (the scatter diameter is about $149.27 \mathrm{~mm}$ ), but the number of fragments penetrating the third target plate is obviously reduced, resulting in less impact craters on the fourth target plate.

It can be seen from Figure 8 that when the impact velocity is $450 \mathrm{~m} / \mathrm{s}$, the plug formed after radial layered PELE penetrates the first target plate does not squeeze into the filling, and the deformation of the penetrator is small. The damage of the penetrator to the witness plates is mainly the plugging failure. The diameters of perforations on the second, third and fourth layers of target plate are $19.79 \mathrm{~mm}, 20.62 \mathrm{~mm}$ and $14.84 \mathrm{~mm}$ respectively, the diameters of plastic area are $176.90 \mathrm{~mm}, 173.60 \mathrm{~mm}$ and $58.97 \mathrm{~mm}$ respectively, and the uplift heights of plastic area are $14.84 \mathrm{~mm}, 13.61 \mathrm{~mm}$ and $14.84 \mathrm{~mm}$ respectively. When the impact velocities are $650 \mathrm{~m} / \mathrm{s}, 850 \mathrm{~m} / \mathrm{s}$ and $1050 \mathrm{~m} / \mathrm{s}$, the head of the outer jacket begins to break after the penetrator penetrates the first target plate, and the remaining penetrator and the generated fragments form large perforations on the second target plates, with the perforation diameter of $33.81 \mathrm{~mm}, 46.60 \mathrm{~mm}$ and $65.15 \mathrm{~mm}$ respectively. After penetrating the second target plate, the outer jacket of the penetrator continues to break, while the head of the inner jacket also begins to break. The third target plate has a small perforation, but there are also a lot of impact craters around the perforation, which are $82.47 \mathrm{~mm}, 145.56 \mathrm{~mm}$ and $117.11 \mathrm{~mm}$ in diameter respectively.

From the comparison of the fragmentation of non layered PELE and radial layered PELE and their damage to the witness plates after penetrating the main target plate of $2 \mathrm{~A} 12$ aluminum alloy with the thickness of $5 \mathrm{~mm}$, it is can be concluded that under the same impact velocity, the deformation and fragmentation degree of radial layered PELE is smaller than that of non layered PELE. The perforation diameter of the penetrator on each target plate and the distribution diameter of the impact craters on the third target plate are shown in Table 2. non layered PELE and radial layered PELE all causes great damage to the witness plates, but after penetrating the fourth target, the volume of the remaining penetrator of radial layered PELE is larger than that of non layered PELE, and it still has a strong penetration ability. Radial layered PELE has stronger penetration ability than non layered PELE. 


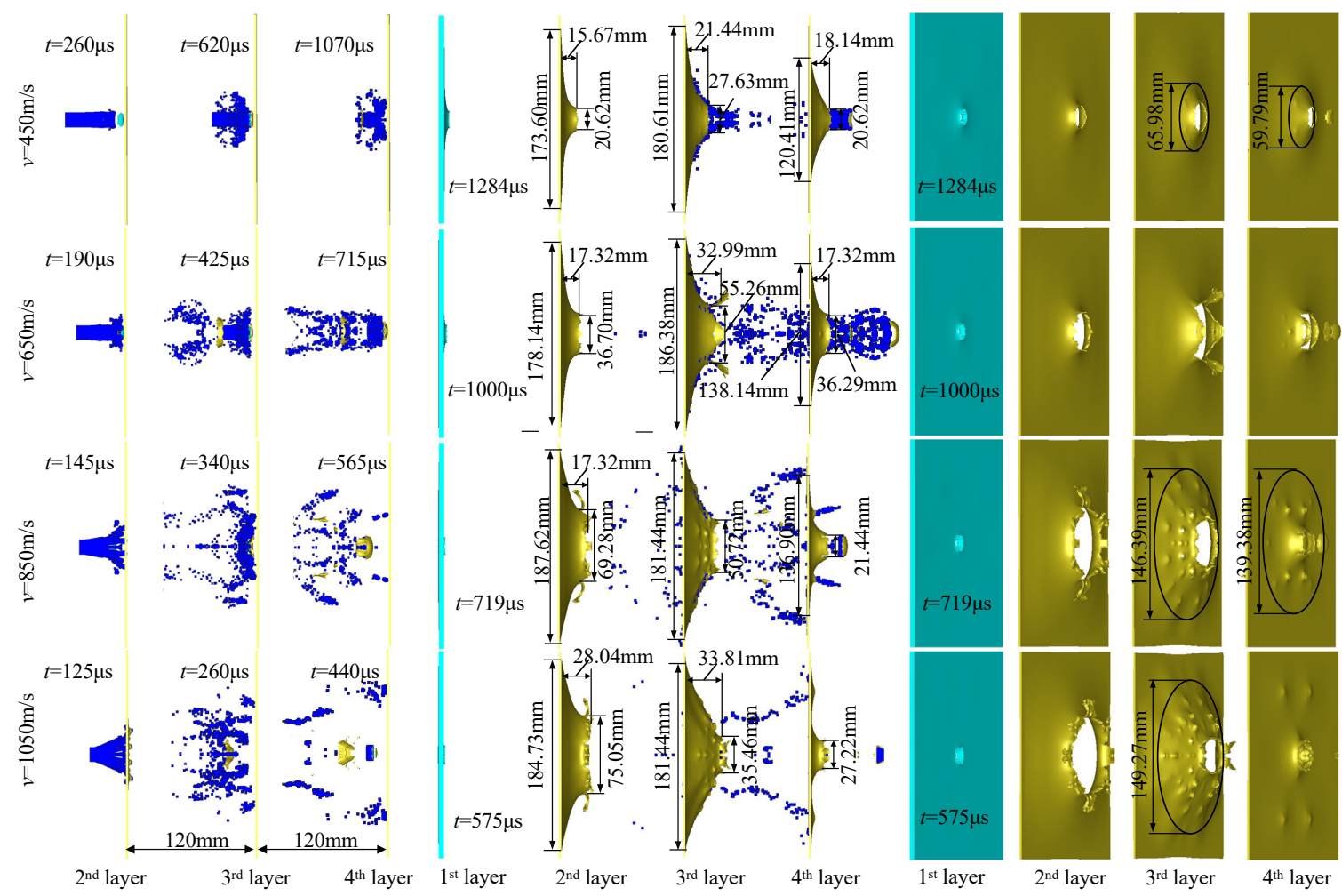

Figure 7 Fragmentation and damage to the witness plates of non layered PELE after penetrating the main target plate of $2 \mathrm{~A} 12$ aluminum alloy with the thickness of $5 \mathrm{~mm}$ at different velocities

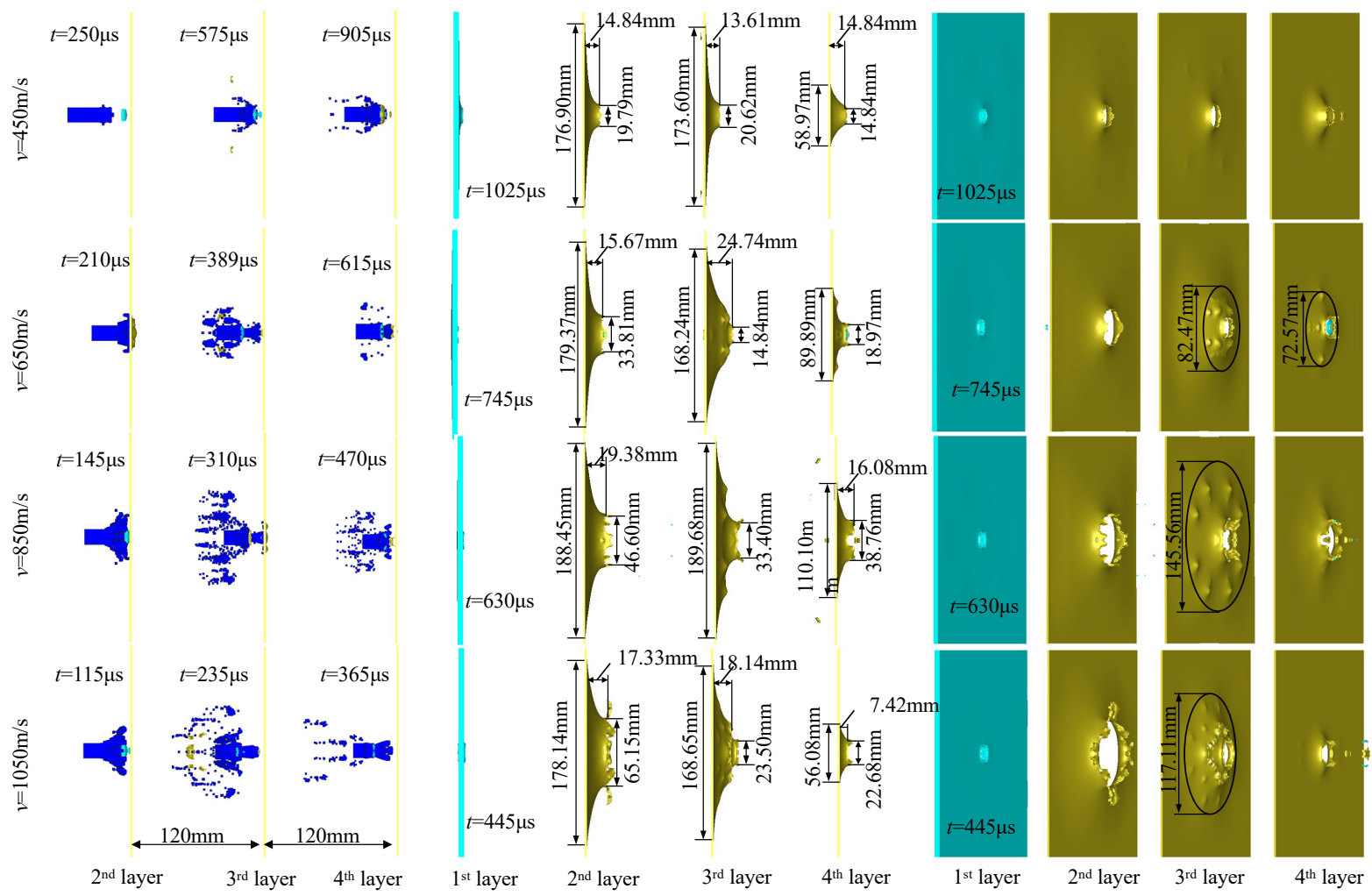

Figure 8 Fragmentation and damage to the witness plates of radial layered PELE after penetrating the main target plate of $2 \mathrm{~A} 12$ aluminum alloy with the thickness of $5 \mathrm{~mm}$ at different velocities 
Table 2 Diameter of perforation on each target plate and the distribution diameter on the third target plate (the material of the main target plate is $2 \mathrm{~A} 12$ aluminium alloy)

\begin{tabular}{cccccc}
\hline $\begin{array}{c}\text { Type of } \\
\text { PELE }\end{array}$ & $\begin{array}{c}\text { Impact } \\
\text { velocity(m/s) }\end{array}$ & $\begin{array}{c}\text { Perforation diameter } \\
\text { on the second } \\
\text { layer(mm) }\end{array}$ & $\begin{array}{c}\text { Perforation diameter } \\
\text { on the third layer(mm) }\end{array}$ & $\begin{array}{c}\text { Perforation diameter } \\
\text { on the fourth } \\
\text { layer(mm) }\end{array}$ & $\begin{array}{c}\text { Distribution diameter of the } \\
\text { impact craters on the third layer } \\
\text { (mm) }\end{array}$ \\
\hline \multirow{3}{*}{ Non } & 450 & 20.62 & 27.63 & 20.62 & 65.98 \\
layered & 650 & 36.70 & 55.26 & 36.29 & -- \\
& 850 & 69.28 & 50.72 & 21.44 & 146.39 \\
& 1050 & 75.05 & 35.46 & 27.22 & 149.27 \\
Radial & 450 & 19.72 & 20.62 & 14.84 & -- \\
layered & 650 & 33.81 & 14.84 & 18.97 & 82.47 \\
& 850 & 46.60 & 33.40 & 38.74 & 145.56 \\
\hline
\end{tabular}

Figure 9 and Figure 10 show the fragmentation and damage to the witness plates of non layered PELE and radial layered PELE after penetrating the main target plate of Q235 steel with the thickness of $5 \mathrm{~mm}$ at different velocities. It can be seen from Figure 9 that with the increase of impact velocity, the more serious the penetrator is broken. When the impact velocity is $450 \mathrm{~m} / \mathrm{s}$, the penetrator is gradually broken during the penetrating process, but the penetrator is not completely broken after penetrating the fourth target plate. Punch holes and plastic bulges are formed on the second, third and fourth target plates, the diameter and plastic deformation are gradually increased. The height of plastic bulges are $17.32 \mathrm{~mm}, 18.97 \mathrm{~mm}$ and $28.04 \mathrm{~mm}$, respectively, which shows that the remaining penetrator and fragments have a great synergy damage ability.

When the impact velocity is $650 \mathrm{~m} / \mathrm{s}$, the penetrator breaks seriously after penetrating the first target plate, forming a large tear perforation on the second target plate (the diameter is about $54.43 \mathrm{~mm}$ ). After penetrating the second target plate, the penetrator is completely broken into debris cloud, but the distribution of debris cloud in the radial direction is relatively concentrated, so the diameter of perforation formed on the third target plate is just slightly larger than that on the second target plate (about $61.03 \mathrm{~mm}$ ). When the debris cloud penetrates the third target plate, a large number of small pieces are blocked. Only the round cake part of the jacket of the penetrator and a small number of large pieces penetrate the third target plate, forming a small perforation (the diameter of the perforation is about $27.22 \mathrm{~mm}$ ) and plastic deformation on the fourth target plate. When the impact velocities are $850 \mathrm{~m} / \mathrm{s}$ and $1050 \mathrm{~m} / \mathrm{s}$, the penetrator breaks violently after penetrating the first target plate, forming very large tear holes on the second target plate, with the diameter of $86.59 \mathrm{~mm}$ and $81.23 \mathrm{~mm}$ respectively. After penetrating the second target plate, a relatively scattered debris cloud is formed, which leaves a large number of impact craters on the third target plate, with the diameter of $164.94 \mathrm{~mm}$ and $136.08 \mathrm{~mm}$, respectively. However, due to the small average mass of debris, the perforations formed on the third target plate are small, with the diameter of $21.85 \mathrm{~mm}$ and $25.57 \mathrm{~mm}$, respectively.

When the impact velocity is $850 \mathrm{~m} / \mathrm{s}$, the perforation on the third target plate is mainly formed by the impact of the round part at the bottom of the of the jacket, and at $674 \mu \mathrm{s}$, only the round cake part of the jacket penetrates the fourth target plate, and the rest fragments fail to penetrate the third target plate. When the impact velocity is $1050 \mathrm{~m} / \mathrm{s}$, the round part at the bottom of the jacket is also broken. The perforation on the third target plate is formed by the collaborative impact of the fragments in the center of the debris cloud. Only a small number of fragments can penetrate the third target plate and form a small number of fragment perforation and impact crater on the fourth target plate.

Figure 10 shows that radial layered PELE causes a large degree of damage to both the main target plate and the witness plates. When the impact velocity is $450 \mathrm{~m} / \mathrm{s}$, the penetrator only breaks slightly at the head, and the penetrator still keeps a good shape after penetrating the four interval target plates. The perforations with the almost same size are formed on the witness plates. The diameters of perforations on the second, third and fourth target plates are $97.79 \mathrm{~mm}, 20.21 \mathrm{~mm}$ and $20.21 \mathrm{~mm}$ respectively. When the impact velocity is larger $(650 \mathrm{~m} / \mathrm{s}, 850 \mathrm{~m} / \mathrm{s}, 1050 \mathrm{~m} / \mathrm{s})$, the outer jacket breaks after penetrating the first target plate, and the breaking degree of the outer jacket increases with the increase of impact velocity.

When the impact velocities are $650 \mathrm{~m} / \mathrm{s}$ and $850 \mathrm{~m} / \mathrm{s}$, the penetrator not only has a large tear perforation on the second target plate, but also has a number of small holes formed by the impact of small fragments around the tear perforation. The diameters of the tear perforations are $32.99 \mathrm{~mm}$ and $67.21 \mathrm{~mm}$ respectively, and the dispersion diameters of small holes are $75.46 \mathrm{~mm}$ and $107.21 \mathrm{~mm}$ respectively. When the impact velocity is $1050 \mathrm{~m} / \mathrm{s}$, the outer jacket of the penetrator is severely broken after penetrating the first main target plate. The debris cloud formed by the fragmentation of the outer jacket work together with the residual penetrator, forming a perforation with the diameter of $94.84 \mathrm{~mm}$ on the second target plate and the edge of perforation is uneven. When the impact velocities are $650 \mathrm{~m} / \mathrm{s}$, 
$850 \mathrm{~m} / \mathrm{s}$ and $1050 \mathrm{~m} / \mathrm{s}$ respectively, after the penetrates the second target plate, the outer jacket of the penetrator is further broken, and the inner jacket is gradually deformed, expanded and broken, forming larger perforation (diameters are about $27.22 \mathrm{~mm}, 37.11$ and 54.84 respectively) and large distribution area of impact craters by the fragments (distribution diameters are about $108.45 \mathrm{~mm}, 107.62 \mathrm{~mm}$ and $140.20 \mathrm{~mm}$ respectively) on the third target plate. When the impact velocity is $650 \mathrm{~m} / \mathrm{s}$, a perforation with a diameter of about $18.97 \mathrm{~mm}$ and a plastic deformation area with a diameter of about $51.96 \mathrm{~mm}$ are formed on the fourth target plate; when the impact velocity is $850 \mathrm{~m} / \mathrm{s}$, a perforation with a diameter of about $31.99 \mathrm{~mm}$ and a dispersion area of small perforations with a diameter of about $94.84 \mathrm{~mm}$ are formed on the fourth target plate; and when the impact velocity is $1050 \mathrm{~m} / \mathrm{s}$, a perforation with a diameter of about $25.15 \mathrm{~mm}$ and a spread area perforation of impact craters with a diameter of about $103.09 \mathrm{~mm}$ are formed on the fourth target plate. This shows that radial layered PELE has also caused serious damage to the fourth target plate, and after penetrating the four interval metal target plates, the PELE still has a relative large volume of residual penetrator and a certain number of flying fragments, which still has damage ability.

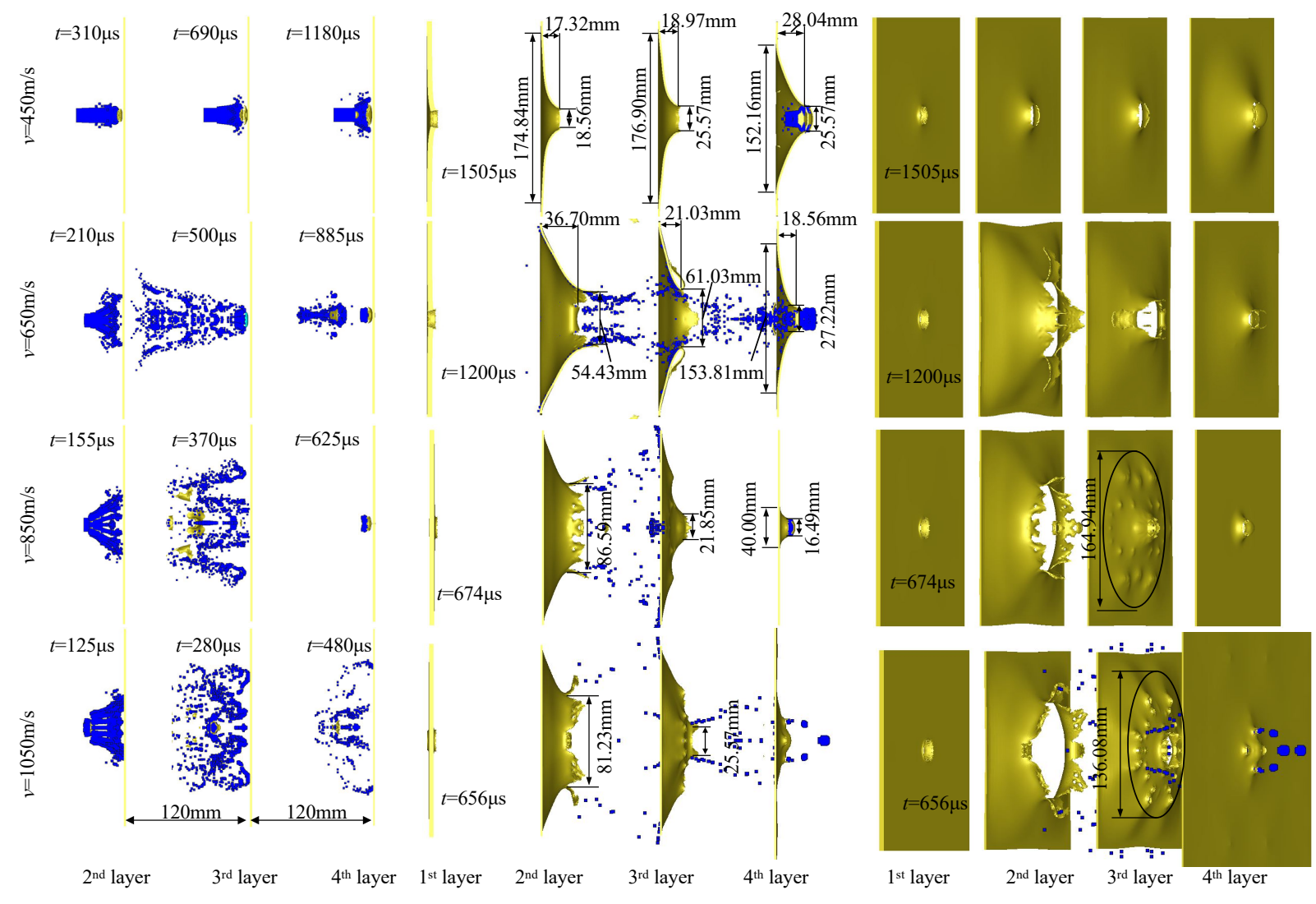

Figure 9 Fragmentation and damage to the witness plates of non layered PELE after penetrating the main target plate of Q235 steel with the thickness of $5 \mathrm{~mm}$ at different velocities

From the comparison of the fragmentation of non layered PELE and radial layered PELE and their damage to the witness plates after penetrating the main target plate of Q235 steel with the thickness of $5 \mathrm{~mm}$, and the diameter of perforation and impact craters distribution on the second, third and fourth target plates (as shown in Table 3), it is can be concluded that under the same impact velocity, the two kind of PELE all have good damage effect on the second and third target plates, But the damage degree of the fourth target plate by radial layered PELE is much higher than that by non layered PELE, moreover, radial layered PELE still has a relative large volume of residual penetrator and a certain number of flying fragments after penetrating the four spaced metal target plate. Compared with the situation of the main target plate is 2A12 aluminum alloy with the thickness of $5 \mathrm{~mm}$, under the same impact velocity, the deformation and fragmentation degree of radial layered PELE after penetrating the main target plate of Q235 steel with the thickness of $5 \mathrm{~mm}$ and the damage degree of the three witness metal plates are all greater. 


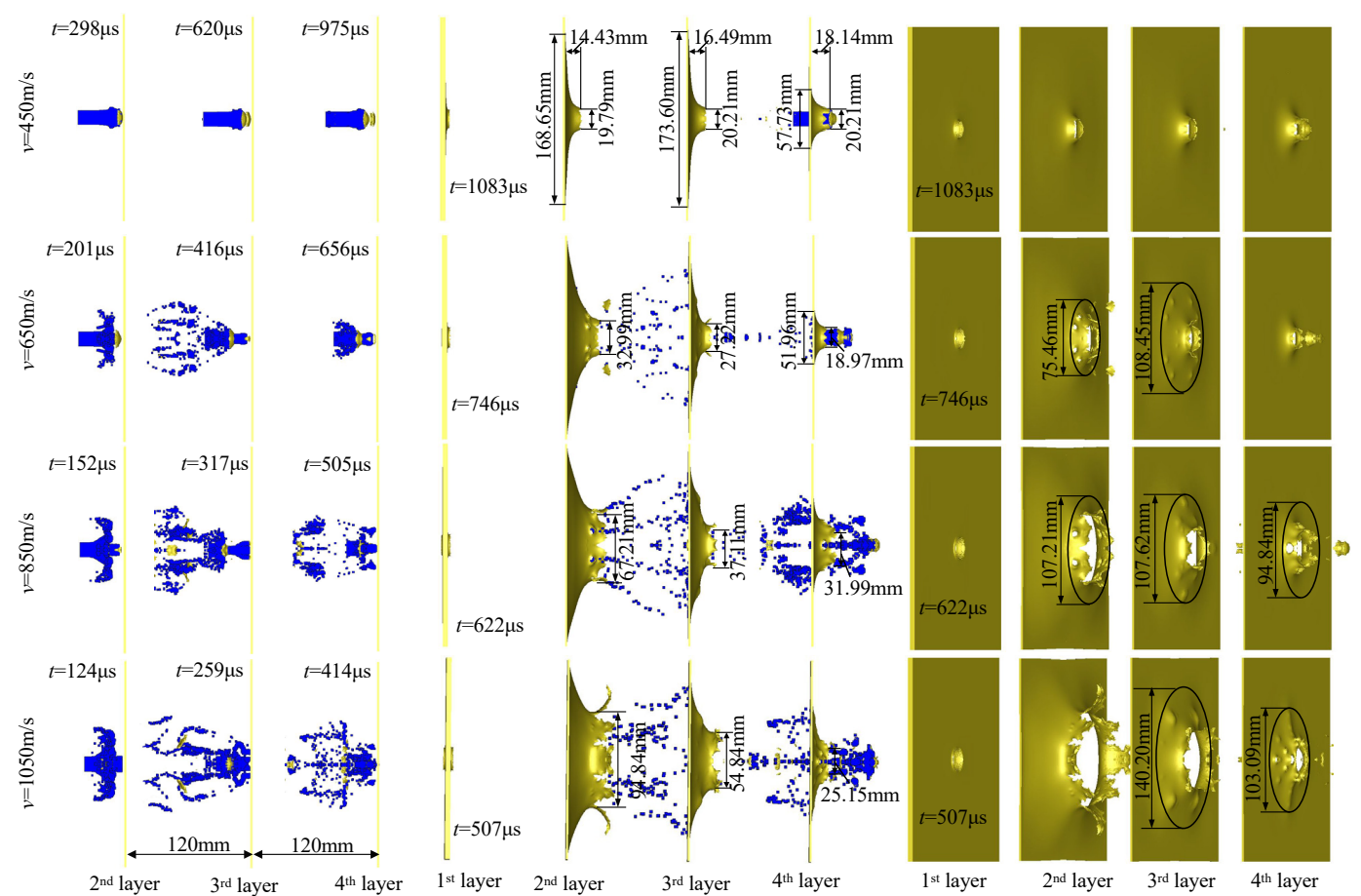

Figure 10 Fragmentation and damage to the witness plates of radial layered PELE after penetrating the main target plate of Q235 steel with the thickness of $5 \mathrm{~mm}$ at different velocities

Table 3 Diameter of perforation and distribution of the impact craters on each witness plate (the material of the main target plate is Q235 steel)

\begin{tabular}{ccccc}
\hline $\begin{array}{c}\text { Type of } \\
\text { PELE }\end{array}$ & $\begin{array}{c}\text { Impact } \\
\text { velocity(m/s) }\end{array}$ & $\begin{array}{c}\text { Perforation diameter/distribution } \\
\text { diameter of the impact craters on } \\
\text { the second layer(mm) }\end{array}$ & $\begin{array}{c}\text { Perforation } \\
\text { diameter/distribution diameter } \\
\text { of the impact craters on the third } \\
\text { layer(mm) }\end{array}$ & $\begin{array}{c}\text { Perforation } \\
\text { diameter/distribution diameter } \\
\text { of the impact craters on the } \\
\text { fourth layer(mm) }\end{array}$ \\
\hline \multirow{2}{*}{ Non } & 450 & $18.56 /--$ & $25.57 /--$ & $25.57 /--$ \\
layered & 650 & $54.43 /--$ & $61.03 /--$ & $27.22 /--$ \\
& 1050 & $86.59 /--$ & $21.85 / 164.94$ & $16.49 /--$ \\
& 450 & $81.23 /--$ & $25.57 / 136.08$ & $--/--$ \\
Radial & 650 & $19.79 /--$ & $20.21 /--$ & $20.21 /--$ \\
layered & 850 & $32.99 / 75.40$ & $27.22 / 108.45$ & $18.97 /--$ \\
& 1050 & $67.21 / 107.21$ & $37.11 / 107.62$ & $31.99 / 94.84$ \\
\hline
\end{tabular}

\section{CONCLUSION}

In this paper, the experimental and numerical simulation were used to study the deformation and fragmentation of the radial layered and non layered PELE after penetrating 2A12 aluminum alloy target plate or Q235 steel target plate at different velocities, as well as the damage to the witness plates and damage capacity of penetrator to multi-layer metal target plates. The simulation results are in good agreement with the experimental results. Several conclusions can be obtained from these simulations and experiments:

(1) Non layered PELE is seriously broken after penetrating the multi-layer spaced metal plates. Although the first three layers of interval metal target plate are seriously damaged, the volume of residual penetrator after penetrating the first three layers of interval metal target plate is small, the number of fragments is small, so the damage ability of the penetrator to the fourth target plate is significantly reduced, and it is difficult to have a good damage ability to the high value targets behind the fourth target plate. However, the outer jacket of radial layered PELE is seriously broken in the process of passing through the four spaced metal plates, and a large number of fragments are produced, which cause great damage to the four spaced metal plates, but the deformation degree of the inner jacket and the rear jacket is 
relatively small. After passing through the four spaced metal plates, radial layered PELE still has a large volume of residual penetrator with a high residual velocity and a certain number of flying fragments, which can continue to cause serious damage to the high value targets behind the four interval metal target plates.

(2) Compared with the situation of the main target plate is $2 A 12$ aluminum alloy with the thickness of $5 \mathrm{~mm}$, under the same impact velocity, the deformation and fragmentation degree of radial layered PELE after penetrating the main target plate of Q235 steel with the thickness of $5 \mathrm{~mm}$ and the damage degree of the witness metal plates are all greater. With the increase of impact velocity, the deformation and fragmentation degree of radial layered PELE are increased, and the diameter of fragments dispersion is also increased.

(3) In the process of penetrating multi-layer spaced metal plates, the outer jacket of radial layered PELE gradually breaks up to form a large number of flying fragments, but the inner jacket is difficult to deform and break, so the penetrator maintains a strong penetration ability. Therefore, for multi-layer spaced metal plates, radial layered PELE has a better penetration and damage capacity than non layered PELE.

\section{Acknowledgments:}

The work was supported by National Natural Science Foundation of China (Grant No. 11802141, 11802130), Natural Science Foundation of Jiangsu Province (Grant No. BK20170819) .

Author's Contributions: Conceptualization, C Cheng, Z Du, L Xu and Z Pang; Methodology, C Cheng, Z Du and C Du; Investigation, C Cheng, Z Du, X Chen and Z Pang; Writing - original draft, C Cheng, Z Pang and L Xu; Writing - review \& editing, Z Pang and Z Du; Formal analysis, $C$ Cheng, $C$ Du and $Y$ Sun; Funding acquisition, $Z$ Pang and $X$ Chen; Project administration, $X$ Chen and $Z$ Pang; Software, C Cheng, LXu and Y Sun; Supervision, X Chen and Z Du; Data curation, C Cheng, L Xu and Y Sun.

Editor: Marcílio Alves.

\section{References}

Cheng, C., Du, Z. H., Chen, X. et al. (2019). Simulation of fragmentation characteristics of projectile jacket made of tungsten alloy after penetrating metal target plate using SPH method. Defence Science Journal 69: 591-598.

Cheng, C., Du, Z. H., Chen, X. et al. (2020). Damage of Multi-layer spaced Metallic Target plates Impacted by Radial Layered PELE, Defence Technology 16:201-207.

Ding, L. L., Zhou, J. Y., Tang, W. H.,et al. (2018a). Research on the Crushing Process of PELE Casing Material Based on the CrackSoftening Algorithm and Stochastic Failure Algorithm. Materials 11: 1544-1561.

Ding, L. L., Zhou, J. Y., Tang, W. H.,et al. (2018b). Damage Characteristics of PELE Projectile with Gradient Density Inner Core Material, Materials 11: 2370-2389.

Du, Z. H., Song L. L.(2011). Theoretical Model of Penetrator with Enhanced Lateral Effect Impacting Thin Metal Target[J]. Journal of Nanjing University of Science and Technology (Natural Science) 035:822-826.

Fan, Z. J., Ran, X. W., Tang, W. H., et al. (2016). The model to calculate the radial velocities of fragments after PELE penetrator perforating a thin plate. International Journal of Impact Engineering 95:12-16.

Fan, Z. J., Ran, X. W., Tang, W. H., et al. (2017a). method and influencing factors of the fragmental radial velocities of PELE after penetrating thin target. Explosion and shock waves 37, 621-628.

Fan, Z. J., Ran, X. W., Tang, W. H., et al. (2017b). A study on fragmentation distribution of PELE. Journal of Vibration and shock 36: 72-77.

Jimmy, V. (2015). Analytical and numerical description of the PELE fragmentation upon impact with thin target plates. International Journal of Impact Engineering 76:196-206.

Liu, N., Cui, X., Xiao, J., Lua, J., et al. (2020). A simplified continuum damage mechanics based modeling strategy for cumulative fatigue damage assessment of metallic bolted joints. International Journal of Fatigue 131, 105302.1-105302.10. 
Liu, N., Jeffers, A. E. (2018). Adaptive isogeometric analysis in structural frames using a layer-based discretization to model spread of plasticity. Computers \& Structures 196:1-11.

Liu, N., Jeffers, A. E. (2019). Feature-preserving rational bezier triangles for isogeometric analysis of higher-order gradient damage models. Computer Methods in Applied Mechanics and Engineering 357, 112585.1-112585.19.

Meyers, M. A., Marr, L. E. (1982). Shock waves and high-strain-rate phenomena in metals. Journal of Mechanical Working Technology 6, 398-399.

Mott, N.F. (1947). Fragmentation of shell cases. Proce. Royal Soc. London. Series A, Math. Phys. Sci. 189: 300-308.

Moxnes, J., Steinar, B. (2015). Simulation of natural fragmentation of rings cut from warheads. Defence Technology 11: 319-329.

Paulus, G., Schirm, V. (2006). Impact behaviour of PELE projectiles perforating thin target plates. International Journal of Impact Engineering 33:566-579.

Rohr, I., Nahme, H., Thoma, K. et al. (2008). Material characterisation and constitutive modelling of a tungsten-sintered alloy for a wide range of strain rates. International Journal of Impact Engineering 35: 811-819.

Xu, L. Z., Cheng, C., Du, C. X., et al. (2020). Semi-Crystalline Polymers Applied to Taylor Impact Test: Constitutive, Experimental and FEM Analysis. Ploymers 12, 1-13.

Yin, J. P., Han, Y. Y., Wang, X. F., et al. (2020). A new charge structure based on computer modeling and simulation analysis, Journal of Visual Communication and Image Representation 64:1-10.

Zhang, W., Wei, G., Xiao, X. K., (2013). Constitutive relation and fracture criterion of 2A12 aluminum alloy, acta Armamentarii 34:276-282.

Zhu, J. S., Zhao, G. Z., Du, Z. H. (2007). Influence of the filling material on the PELE effect. Journal of Ballistics 19:62-65.

Zhu, J. S., Zhao, G. Z., Du, Z. H. (2009a). Influence of Projectile Configuration on Functionary Effect of PELE. journal of system simulation 21: 39-42.

Zhu, J. S., Zhao, G. Z., Du, Z. H. (2009b). Influence of Projectile Configuration on Functionary Effect of PELE, Journal of System Simulation 1: 39-42. 